\title{
In vitro characterization of the full-length human dynein-1 cargo adaptor BicD2
}

Robert Fagiewicz ${ }^{1,2,3,4}$, Corinne Crucifix ${ }^{1,2,3,4}$, Célia Deville ${ }^{1,2,3,4}$, Bruno Kieffer ${ }^{1,2,3,4}$, Yves Nomineé $1,2,3,4$, Johan Busselez $z^{1,2,3,4}$, Paola Rossolilo ${ }^{1,2,3,4}$, Helgo Schmidt ${ }^{1,2,3,4}$

1. Institut de Génétique et de Biologie Moléculaire et Cellulaire, Integrated Structural Biology Department, Illkirch, France

2. Centre National de la Recherche Scientifique, UMR7104, Illkirch, France

3. Institut National de la Santé et de la Recherche Médicale, U1258, Illkirch, France

4. Université de Strasbourg, Illkirch, France

\begin{abstract}
The cargo adaptors are crucial in coupling motor proteins with their respective cargos and regulatory proteins. BicD2 is one of the most prominent examples within the cargo adaptor family. BicD2 is able to recruit the microtubule motor dynein to RNA, viral particles and nuclei. The BicD2-mediated interaction between the nucleus and dynein is implicated in mitosis as well as interkinetic nuclear migration (INM) in radial glial progenitor cells, and neuron precursor migration during embryonic neocortex development. In vitro studies involving full-length cargo adaptors are difficult to perform due to the hydrophobic character, low-expression levels, and intrinsic flexibility of cargo adaptors. Here we report the recombinant production of full-length human BicD2 and confirm its biochemical activity by interaction studies with RanBP2 and cytoplasmic dynein-1. We also describe $\mathrm{pH}$-dependent conformational changes of BicD2 using cryoEM, template-free structure predictions, and biophysical tools. Our results will help defining the biochemical parameters for the invitro reconstitution of higher order BicD2 protein complexes.
\end{abstract}

\section{INTRODUCTION}

Cytoplasmic dynein drives the majority of retrograde microtubule transport events in eukaryotic cells. The main isoform - cytoplasmic dynein-1 (hereafter dynein-1) is involved in cell division, the transport of organelles and vesicles, brain and muscle development, and can also be hijacked by pathogenic viruses to reach cellular locations ${ }^{1,2,3,4,5}$. It is a particularly interesting motor in neurons, as it carries essential signals and organelles from distal axon sites to the cell body ${ }^{6}$.

During mitosis, the dynein cargo adaptor BicD2 binds to the nucleus and recruits dynein1 and dynactin (DDB complex) to ensure proper positioning of the nucleus relative to the centrosome $^{7}$. In the developing human neocortex, the DDB complex is recruited to the nucleus of radial glial progenitor cells during interkinetic nuclear migration (INM) between 
the apical and the basal side of the neocortex $8,7,9$. The INM takes place within the ventricular zone of the neocortex and has been shown to be essential for the mitotic generation of neuron progenitors that drive neocortex development. The INM movement is driven by the motor proteins kinesin-1 and dynein-1. Impairment of either motor protein causes severe defects in neuronal migration and nuclear movements, which can further lead to neuropathologies such as lissencephaly or microcephaly ${ }^{10,11,12}$.

The BicD2 cargo adaptor is an elongated, flexible linker protein that connects the dynein1/dynactin complex during the nuclear pore component RanBP2 (Nup358) (Figure1A) during INM. It has been shown in vivo and in vitro that BicD2 is recruited to RanBP2 in a CDK1-dependent manner ${ }^{9}$. The CDK1-mediated phosphorylation of RanBP2 significantly increases the interaction with BicD2.

The full-length human isoform 2 of the BicD2 is composed of 855 amino acids and is divided into three coiled-coil (CC) domains $\mathrm{CC} 1, \mathrm{CC} 2$, and $\mathrm{CC} 3$ (Figure 1B). BicD2 dimerizes via its $\mathrm{CC}$ domains. The $\mathrm{N}$-terminal $\mathrm{CC} 1$ domain contains the dynein and dynactin interacting motifs - the CC1 box ${ }^{13,14,15}$ and the spindly motif ${ }^{13,16,17}$. The CC2 and CC3 domains are mediating the interaction with the microtubule plus-end motor kinesin1, nuclear pore components, clathrin heavy chain, RNA, and viral particles ${ }^{7,18,19,20,21,22,23,24}$. BicD2 adopts an auto-inhibited conformation in the absence of cargo, which prevents its interaction with dynein/dynactin. Cargo binding to BicD2 overcomes autoinhibition and allows the recruitment of dynein/dynactin leading to robust motility of DDB complexes in in vitro single-molecule assays. ${ }^{25}$

The structural basis for BicD2 auto-inhibition has been investigated in early studies on BicD2, BicD1, and Drosophila BicD. In the absence of cargo the $\mathrm{N}$ - and C-terminal parts of BicD2 are believed to contact each other potentially preventing the interaction with partner proteins $26,27,28,7,29,30,31,32,33$. Recent reports have indicated that the cargo-induced switch from the auto-inhibited to open - the activated BicD2 form, might proceed via a registry shift in its CC3 domain ${ }^{34}$.

Understanding the structure, dynamics and reactivity of cargo adaptor proteins is required to advance our understanding of cargo selection, recruitment, and release. Most of the in vitro reconstitution experiments of the human BicD2 with cargo and/or dynein-dynactin were performed on a truncated protein or the Drosophila ortholog. As it is an extensively studied dynein adaptor, there is a need for a protocol for the robust production of fulllength human BicD2. The long-standing challenges in characterising cargo adaptors like BicD2 are limited expression levels and solubility which makes them poor targets for structural and functional analyses. Here we describe the recombinant production of the human full-length BicD2 and provide novel insights to its in vitro behaviour. We characterize the protein with SEC-MALS, differential scanning fluorimetry, circular dichroism, cryoEM, and template-free structure predictions. Our findings reveal unexpected $\mathrm{pH}$-dependent conformational heterogeneity of BicD2. We also address the biochemical activity of BicD2 by interaction studies with RanBP2 and dynein/dynactin. 
Our findings lay the ground for further studies on BicD2 reactivity, regulation, and role in motor protein complexes formation.

\section{RESULTS}

\section{Biochemical characterization of full length BicD2}

We succeeded in producing full-length human BicD2 isoform 2 under mild solubilizing conditions (see methods) and subsequently characterized its biochemical and functional properties. Our size-exclusion multi-angle might scattering (SEC-MALS) analysis indicates a molecular weight of $192 \mathrm{kDa}$, which is in agreement with the expected value of $186 \mathrm{kDa}$ for a full-length BicD2 dimer (Supplementary figure 1A). BicD2 elutes at a volume of $1.35 \mathrm{~mL}$ on a Superose ${ }^{\circledR} 6$ Increase $3.2 / 300$ size exclusion column, which is earlier than expected and most likely caused by the increased hydrodynamic radius due to the extended coiled-coil fold of BicD2.

We evaluated the effect of buffers on the stability of BicD2 by differential scanning fluorimetry (DSF) to establish an optimal buffer composition. The $\mathrm{pH}$ screen revealed that the BicD2 stability varies considerably in the range from pH 6.0 to $\mathrm{pH} 8.0$ (Figure 2A). The melting curves at $\mathrm{pH} 7.0$ and $\mathrm{pH} 8.0$ show clear but distinct inflection points, while the curve at $\mathrm{pH} 6$ indicates partly unfolded protein. We also performed three SEC runs on full-length BicD2 at $\mathrm{pH} 6.0,7.0$, and 8.0. The elution profile at $\mathrm{pH} 7.0$ and $\mathrm{pH} 8.0$ was characterized by an elution peak for dimeric BicD2 between $1.3-1.4 \mathrm{~mL}$ and a broad peak of degraded BicD2 around $1.8 \mathrm{~mL}$ (Figure 2B). The slightly different SEC elution volumes and the distinct inflection points in the DSC melting curves suggest the possibility of different BicD2 conformations at $\mathrm{pH} 7.0$ and $\mathrm{pH}$ 8.0. Moreover protein ran at $\mathrm{pH} 7.0$ had significantly higher ratio of BicD2 to degrading protein compared to $\mathrm{pH} 8.0$ where degradation proceeds more rapidly (Supplementary figure 1B). At pH 6.0 BicD2 eluted almost at the end of the column suggesting partial denaturation (Figure 2B). Re-running the BicD2 peak fractions revealed elution peaks at the expected volumes without additional degradation peaks. These results were further confirmed by circular dichroism (CD) experiments. The spectra for $\mathrm{pH} 7.0$ and $\mathrm{pH} 8.0$ suggest almost pure $\alpha$-helical content, consistent with the predicted BicD2 fold. The CD spectrum for $\mathrm{pH} 6.0$ does not resemble the $\alpha$-helical model, but also does not fit into random-coil models. Heating the protein up to $60{ }^{\circ} \mathrm{C}$ did not reveal the random coil characteristic peaks (Supplementary figure 2). This suggests that the protein at pH 6.0 adopts a not fully folded structure.

\section{Influence of pH value on BicD2's conformation and stability}

In order to obtain insights into the conformation of $\mathrm{BicD} 2$ at $\mathrm{pH} 7.0$ and $\mathrm{pH} 8.0$, we directly visualized BicD2 at these $\mathrm{pH}$ values using a cryo-electron microscope. We collected two datasets and applied identical data processing workflows to avoid bias in the interpretation. The representative $2 \mathrm{D}$ classes showed that most molecules at $\mathrm{pH} 8.0$ fall 
into an extended conformation (Figure 2D), whereas the vast majority of BicD2 particles adopt more compact conformations (Figure 2E) at $\mathrm{pH} 7.0$. These results are consistent with the results from the SEC runs where BicD2 elutes at $1.4 \mathrm{~mL}$ at $\mathrm{pH} 7.0$ but $1.35 \mathrm{~mL}$ at $\mathrm{pH} 8.0$ suggesting a shorter hydrodynamic radius at $\mathrm{pH} 7.0$.

Next we wanted to identify amino-acid residues that potentially could be responsible for the $\mathrm{pH}$ dependent conformational changes of BicD2. We analysed multiple sequence alignments and focused on conserved histidines as they often have crucial functions in $\mathrm{pH}$-sensitive proteins. The alignment of BicD, BicD1's, and BicD2's from various organisms shows only a poor sequence identity of around $10 \%$. However, in the Cterminal part of the $\mathrm{CC} 2$ domain there is a short ' $\mathrm{YH}$ ' sequence motif that is present in all $\mathrm{BicD}$ isoforms (Figure 3A). We generated a structure prediction with AlphaFold2 ${ }^{35}$ for the CC2 and CC3 domain of the human BicD2 (Figure 3B) to evaluate where these residues are potentially located within the predicted structure. Our analysis suggests that they are not involved in dimer interactions, but that they are located within the tri-helical interface of $\mathrm{H} 3, \mathrm{H} 4$, and $\mathrm{H} 5$. We compared the $\mathrm{YH}$-containing motif of $h s B i c D 2$ (Y538-H539) with its two distant isoforms $-D$. melanogaster BicD and C. elegans BicD1. The architecture is very similar for all isoforms. Importantly, in all cases there is another conserved basic residue $(\mathrm{H} 640)$ on the $\mathrm{H} 5$ helix that could interact with residue $\mathrm{Y} 538$ on the $\mathrm{H} 3$ helix (Figure 3C).

To test if the $\mathrm{YH}$ motif and the interhelical tyrosine-histidine pair (Y538-H640) interfere with BicD2's $\mathrm{pH}$ dependent behaviour in-vitro, we generated the H539A/Y538A and $\mathrm{H} 539 \mathrm{~A} / \mathrm{Y} 538 \mathrm{~A} / \mathrm{H} 640 \mathrm{~A}$ mutants and characterized them by SEC at $\mathrm{pH} 7.0$ and $\mathrm{pH}$ 8.0. The fact that the differences in the BicD2 elution peaks do still exist suggests that also the underlying conformational differences are still present. Furthermore, the mutant BicD2 proteins are more prone to degradation, because the equilibrium between the peaks for full-length BicD2 and its degradation products has shifted towards the degradation products. This effect is more pronounced for the H539A/Y538A/H640A triple mutant (Figure 3D). At pH 7.0 the BicD2 fraction is the most abundant, while at pH8.0 the BicD2 fraction significantly decreases and the protein is prone to degradation. Even though $\mathrm{H} 539 / \mathrm{Y} 538 / \mathrm{H} 640$ does not seem to be involved in the $\mathrm{pH}$-induced conformational changes of full-length BicD2, these residues nevertheless are clearly important for the stability of the protein.

\section{BicD2's interaction with RanBP2 and dynein/dynactin}

RanBP2 (or Nup358) is known to recruit BicD2 through a small disordered region between two Ran binding domains (2003-2444) as demonstrated in yeast two-hybrid assays. ${ }^{7}$ The BicD2 binding domain of RanBP2 (hereafter RanBP2 ${ }_{\mathrm{BBD}}$ ) interacts with the C-terminus of BicD2 (715-804) ${ }^{36}$ and contains several consensus CDK1 phosphorylation sites, which have been shown to be important for BicD2 binding. ${ }^{9}$ However, a recent in-vitro experiment demonstrated that the RanBP2 $\mathrm{BBD}-\mathrm{BicD} 2$ complex can also be formed in the 
absence of phosphorylation. ${ }^{36}$ Since all these experiments used the truncated BicD2 Cterminus, the binding of the full-length $\mathrm{BicD} 2$ to $\mathrm{RanBP} 2_{\mathrm{BBD}}$ remains to be characterized. In order to clarify the role of phosphorylation in BicD2- RanBP2 $2_{\text {BBD }}$ complex formation, and to confirm the biochemical activity of our recombinant full-length BicD2, we evaluated the interaction with its binding partner RanBP2.

We performed double pull-down assays with full length BicD2 and RanBP2 $2_{B B D}$ as well as with a phosphomimetic variant of RanBP $2_{B B D}$ where the known CDK1 phosphorylation sites had been mutated to aspartates (T2153D, S2246D, S2251D, S2276D, and S2280D). We were able to obtain a BicD2-RanBP2 (Supplementary figure 3). However, subsequent SEC runs of the purified complexes indicated that they are not stable and that they dissociate. In order to investigate if RanBP2 $2_{\text {BBD }}$ phosphorylation leads to more stable complex formation, we produced recombinant $\mathrm{CDK} 1^{37}$ and performed an in vitro kinase assay on RanBP2 $2_{\mathrm{BBD}}$. The mass spectrometry analysis revealed eight $\mathrm{S} / \mathrm{T}$ consensus sites in the BicD2 binding region of RanBP2 of which five overlapped with earlier findings ${ }^{9}$ (Supplementary figure 4). We mixed in vitro phosphorylated or non-phosphorylated RanBP2 $2_{B B D}$ with full length BicD2 and analysed the samples by SEC. Successful complex formation was only observed for the in vitro phosphorylated RanBP2 (Figure 4A). Next, we investigated if BicD2 can be phosphorylated by CDK1 and if such a modification could potentially strengthen complex

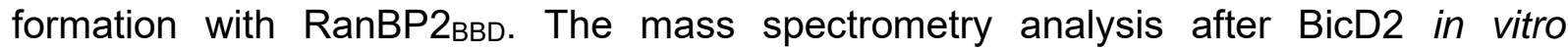
phosphorylation indicated five phosphorylation sites in regions predicted to be structurally disordered demonstrating that BicD2 can be phosphorylated by CDK1 (Supplementary figure 4). We mixed the in vitro phosphorylated BicD2 with non-modified RanBP2 $2_{\mathrm{BBD}}$ and subsequently analysed the sample by SEC. There was no indication of complex formation (Figure 4A). The equivalent experiment with in vitro phosphorylated RanBP2BBD did not show any evidence of increased BicD2-RanBP2 ${ }_{\mathrm{BBD}}$ complex formation compared to nonmodified BicD2 - in vitro phosphorylated RanBP2 SEC run (Figure 4A). These results suggest that BicD2 phosphorylation does not contribute to the BicD2-RanBP2 ${ }_{\text {BBD }}$ complex formation.

We also analysed the influence of $\mathrm{pH}$ on BicD2-RanBP2 $2_{\text {BвD }}$ complex formation. To this end, we mixed full-length BicD2, RanBP2 $2_{\mathrm{BBD}}$ and $\mathrm{CDK} 1$ at $\mathrm{pH} 7.0$ and $\mathrm{pH} 8.0$ to induce complex formation and analysed the samples by SEC. We also carried out the corresponding control experiments in the absence of CDK1 (Figure 4B). From the fractions analysed by SDS-PAGE, it is evident that complex formation is enhanced with CDK1-treated samples. Interestingly, the two runs at pH 7.0 (with and without CDK1) showed a broad distribution of RanBP2 $2_{B B D}$ throughout the elution and only minor increase in the RanBP2 intensity at BicD2 peak fractions in the presence of CDK1. Taken together, these observations suggest that the BicD2-RanBP2 ${ }_{\mathrm{BBD}}$ complex forms best under slightly alkaline $\mathrm{pH}$ which narrows the pool of RanBP2 $\mathrm{BBD}$ species.

Next, we analysed if the complex between full-length BicD2 and RanBP2 interact with dynein/dynactin. We pre-incubated CDK1 phosphorylated RanBP2 $2_{\text {BBD }}$ with 
BicD2 and mixed the complex with freshly prepared rat brain lysate. We pulled on BicD2 and characterized the sample by mass spectrometry. We could identify several dynein and dynactin components, such as dynein-1 heavy chain and p150, which indicated the presence of a dynein/dynactin-BicD2-RanBP2 complex (Supplementary figure 3B).

\section{DISCUSSION}

The ability of Dynein-1 to bind a wide range of cargoes is mediated by its compatibility with many cargo adaptor proteins, such as BicDs, Hooks, NINs, spindly, TRAKs, RILP or JIP3. ${ }^{38}$ Investigating in vitro reconstituted complexes between cargo adaptors and dynein/dynactin has led to valuable insights into dynein motor recruitment and activation. ${ }^{26,27,34}$ However most of these studies were done with truncated BicD2 constructs that lack either the dynein- or the cargo- binding domains. Many biophysical and structural studies have been hampered by the lack of sufficient amounts of full-length cargo adaptors. Here we report a robust method for the recombinant production of a fulllength BicD2 and proof its correct fold and biochemical activity towards the RanBP2 cargo as well as dynein/dynactin. We believe that our results will facilitate in vitro reconstitution approaches of motor-cargo complexes.

One of the unexpected findings was the strong influence of the $\mathrm{pH}$ value on the conformation and stability of full-length BicD2. At pH 6.0, 7.0 and 8.0 BicD2 switches from partially unfolded to compact and to an open conformation. Our cryoEM 2D classification of full-length BicD2 at $\mathrm{pH} 7.0$ indicates that over $50 \%$ of the particles fall into compact classes while the majority of particles at $\mathrm{pH} 8.0$ adopt an open conformation. Recent work has provided evidence that the autoinhibited state is characterized by an interaction between the $\mathrm{CC} 2$ and $\mathrm{CC} 3$ domains. ${ }^{39}$ Although we were not able to assign individual coiled-coil domains in our cryoEM 2D class averages due to the intrinsic flexibility of BicD2, there is the possibility that the more compact $2 \mathrm{D}$ class averages at $\mathrm{pH} 7.0$ might represent the autoinhibited state and the extended conformation at $\mathrm{pH} 8.0$ the open, activated state.

It is not clear if these $\mathrm{pH}$ driven conformational changes are relevant only in vitro or if they also have a physiological relevance. In principle, the cellular $\mathrm{pH}$ value could also trigger $\mathrm{pH}$ dependent conformational changes of the BicD2 cargo adaptor. At the cytosolic $\mathrm{pH}$ value of $\sim 7.2$ most BicD2 molecules would adapt the compact, potentially autoinhibited form and require additional, activating signals to recruit motor proteins and cargo. Conditions that lead to an increase in the intracellular $\mathrm{pH}$, like mitosis and growth factor signalling $40,41,42$, could bypass the need for such signals and activate the BicD2 cargo adaptor on a globular level.

In the case of BicD2 one of the activating signals is believed to be the interaction with its cargos like RanBP2 ${ }^{43,39,25,44}$. Furthermore, post-translational BicD2 modifications might also influence its reactivity. BicD2 contains several consensus phosphorylation sites ${ }^{45}$ and an acetylation site in its $\mathrm{N}$-terminal part ${ }^{46}$. 
We also have identified three conserved residues, $\mathrm{H} 539 / \mathrm{Y} 538 / \mathrm{H} 640$ that contribute to the stability of BicD2. Mutating these amino-acid residues to alanines clearly increased the tendency of BicD2 for self-degradation. Our template-free AlphaFold2 prediction suggest the possibility of $\mathrm{Y} 538 / \mathrm{H} 640$ forming a hydrogen bond that might stabilize the $\mathrm{H} 3-\mathrm{H} 4-\mathrm{H} 5$ a-helical bundle. Disrupting it could trigger partial unfolding and subsequent protein degradation. A similar architecture (Supplementary figure 5) was also observed in a $\mathrm{pH}$ sensitive endotoxins and mutating the equivalent histidine-tyrosine pair mutation lead to protein destabilization and degradation. ${ }^{47}$

We characterized the BicD2 reactivity with its known cargo protein RanBP2. There are conflicting results in the field with respect to the question whether RanBP2 phosphorylation is a requirement for the interaction with BicD2 ${ }^{9,36}$. Our results now reconcile these reports, because they show that BicD2 has the ability to bind both nonphosphorylated as well as phosphorylated RanBP2DDB. In double pull-downs we observed that BicD2 readily interacts with RanBP2 without any protein modification at $\mathrm{pH}$ 7.0 and 8.0. These complexes are nevertheless unstable over SEC. This suggests that there is a weak association of these proteins in vitro in a wide range of conditions. The CDK1 phosphorylation of RanBP2 (but not BicD2) significantly increased the stability of the complex and increase in the $\mathrm{pH}$ value improved the complex homogeneity.

\section{ACKNOWLEDGEMENT}

This research was supported by a LabEx start up grant (ANR-10-LABEX-30-HS) to HS and Boehringer Ingelheim Fonds as well as FRM PhD fellowships to RF. This study was further supported by the grant ANR-10-LABX-0030-INRT, a French State fund managed by the Agence Nationale de la Recherche under the frame program Investissements d'Avenir ANR-10-IDEX-0002-02. The authors acknowledge the support and the use of resources of the French Infrastructure for Integrated Structural Biology (FRISBI) ANR-10INBS-05 and of Instruct-ERIC. We also thank the IGBMC molecular biology and virus service (Nicole Jung and Thierry Lerouge). 


\section{MATERIALS AND METHODS}

\section{Cloning and mutagenesis}

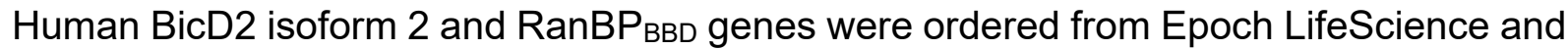
codon-optimized for Escherichia coli expression. The genes were subsequently cloned into the pNHD expression vector (a vector used for site-specific pSer incorporation ${ }^{49}$, but both proteins express equally well in a commercial pMMS vector). The BicD2 plasmid was modified to introduce an N-terminal STREP-tag followed by a short 'GSGSG' linker.

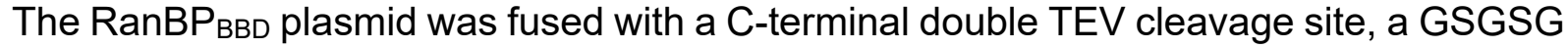
linker, and a 6xHis tag. The H539A/Y538A and H539A/Y538A/H640A mutants were generated by rolling circle PCR. The co-expression plasmid encoding CDK1-cyclinB for insect cell expression was a kind gift from the Andrea Musacchio lab.

\section{Protein expression and purification}

Plasmids for bacterial expression were transformed into E. coli BL21(DE3) chemically competent cells and grown overnight on tetracycline plates. The plate was used for inoculation of the $50 \mathrm{~mL}$ LB medium pre-culture which was grown overnight at $37^{\circ} \mathrm{C}$ medium for further scale-up. Protein expression was induced at $25^{\circ} \mathrm{C}$ with $1 \mathrm{mM}$ isopropyl1-thio- $\beta$-D-galactopyranoside (IPTG) and expressed for $3 \mathrm{~h}$ at $37^{\circ} \mathrm{C}$. Cells were harvested, washed with $1 \mathrm{xPBS}$, and frozen. BicD2 WT and mutants were re-suspended in the lysis buffer containing 1xPBS pH8.0, 10\% glycerol, 7 mM CHAPS, 2 mM DTT, 2mM PMSF, protease inhibitors, and incubated on a roller for $1-2 \mathrm{~h}$ at $4^{\circ} \mathrm{C}$. Cells were lysed by sonication (5x30s with 30s breaks on ice) and centrifuged at $30000 \mathrm{rpm}$ at $4^{\circ} \mathrm{C}$ for 1 hour. The supernatant was mixed with pre-equilibrated STREP-tactin 4XL beads and incubated on a roller for 30 minutes at $4^{\circ} \mathrm{C}$ before loading on a gravity flow column. The resin was washed with $10 \mathrm{CVs}$ of the lysis buffer, $10 \mathrm{CVs}$ of the wash buffer (1xPBS pH8.0,10\% glycerol, $7 \mathrm{mM}$ CHAPS), and eluted with the elution buffer (1xPBS pH8.0, 10\% glycerol, $7 \mathrm{mM}$ CHAPS, $50 \mathrm{mM}$ biotin). Pooled fractions were concentrated to $2 \mathrm{mg} / \mathrm{mL}$ and snapfrozen in $100 \mu \mathrm{L}$ aliquots for further experiments and gel filtration. RanBP2 $2_{\mathrm{BBD}}$ was purified in the same manner as BicD2 with a minor difference in the buffer used $(20 \mathrm{mM}$ Tris- $\mathrm{HCl}$ pH8.0 instead of PBS). Both constructs (WT) yielded around $1 \mathrm{mg}$ of protein per litre of culture (after affinity step).

The CDK1 $1^{\text {CyclinB }}$ plasmid was transformed into E. coli DH10MB-MCherry chemically competent cells with heat shock at $42^{\circ} \mathrm{C}$ for 30 s followed by $6 \mathrm{~h}$ recovery in LB medium at $37^{\circ} \mathrm{C}$ with shaking. The cell were then plated on agar plates containing kanamycin $(50 \mu \mathrm{g}$ $\left.\mathrm{ml}^{-1}\right)$, gentamicin $\left(7 \mu \mathrm{g} \mathrm{ml}^{-1}\right)$, tetracycline $\left(10 \mu \mathrm{g} \mathrm{ml}^{-1}\right)$, Xgal $\left(600 \mu \mathrm{g} \mathrm{ml}^{-1}\right)$ and IPTG (40 $\mu \mathrm{g} \mathrm{ml}^{-1}$ ) and positive clones were identified by a blue/white selection after $24 \mathrm{~h}$ incubation at $37^{\circ} \mathrm{C}$ followed by $24 \mathrm{~h}$ at RT. The positive clones were grown in LB media containing kanamycin $\left(50 \mu \mathrm{g} \mathrm{ml}^{-1}\right)$, gentamicin $\left(7 \mu \mathrm{g} \mathrm{ml}^{-1}\right)$, and tetracycline $\left(10 \mu \mathrm{g} \mathrm{ml}^{-1}\right)$ overnight. Bacmids were purified using the isopropanol precipitation method. $2 \mathrm{ml}$ of Sf9 cells at $0.5 \times 10^{6}$ cells per ml were transfected with $2 \mu \mathrm{g}$ of fresh bacmid DNA and FuGene HD transfection reagent (Promega) at a ratio of 3:1 transfection reagent to DNA. After 72h 
the 6-well plate was analysed for mCherry fluorescence signal and the positive conditions $\left(\mathrm{V}_{0}\right)$ were directly used for further virus amplifications by adding $2 \mathrm{~mL}$ of $\mathrm{V}_{0}$ to $50 \mathrm{~mL}$ of Sf9 cells at $1 \times 10^{6}$ cells per $\mathrm{mL}\left(\mathrm{V}_{1}\right)$ and grown for $72 \mathrm{~h}$. The $\mathrm{V}_{1}$ was then used for infecting another $50 \mathrm{~mL}$ of Sf9 at $1 \times 10^{6}$ cells $/ \mathrm{mL}\left(\mathrm{V}_{2}\right)$. The $\mathrm{V}_{2}$ virus was further used to infect 500 $\mathrm{mL}$ of the Sf9 culture $1 \times 10^{6}$ cells $/ \mathrm{mL}$. After $72 \mathrm{~h}$ the cells were collected at $1000 \mathrm{rpm}$ for $10 \mathrm{~min}$ at $4^{\circ} \mathrm{C}$. The pellet was flash-frozen in liquid nitrogen and stored at $-80^{\circ} \mathrm{C}$ until purification. The CDK1 $1^{\text {CyclinB }}$ pellet was re-suspended in the lysis buffer containing $50 \mathrm{mM}$ Tris- $\mathrm{HCl}$ pH8.0, $10 \mathrm{mM} \mathrm{MgCl}_{2}, 10 \%$ glycerol, 0.1\% NP40, $0.1 \mathrm{mM}$ EDTA, 2mM DTT, 2 $\mathrm{mM}$ PMSF, protease inhibitors, and incubated on a roller for $1 \mathrm{~h}$ at $4^{\circ} \mathrm{C}$. The cells were lysed by sonication (2x30s with 30 s breaks on ice) and centrifuged at $40000 \mathrm{rpm}$ at $4^{\circ} \mathrm{C}$ for 1 hour. The supernatant was mixed with pre-equilibrated GST-sepharose beads for 30 minutes at RT and loaded onto a gravity flow column. The resin was washed with 10 cvs of the lysis buffer, $10 \mathrm{cv}$ ' of the wash buffer (Tris- $\mathrm{HCl}$ pH8.0,150mM NaCl, $10 \%$ glycerol, 0.1mM EDTA), and eluted with the elution buffer (Tris- $\mathrm{HCl} \mathrm{pH} 8.0,150 \mathrm{mM} \mathrm{NaCl}$, $10 \%$ glycerol, $0.1 \mathrm{mM}$ EDTA, $25 \mathrm{mM}$ reduced GST). Pooled fractions were concentrated to $0.5 \mathrm{mg} / \mathrm{mL}$ and snap-frozen in $50 \mu \mathrm{L}$ aliquots for further experiments.

\section{CryoEM sample preparation}

The $100 \mu \mathrm{L}$ sample was thawed on ice and equilibrated with $5 \mathrm{xPBS}$ at either $\mathrm{pH} 8.0$ or $\mathrm{pH}$ 7.0. The Superose ${ }^{\circledR} 6$ Increase column was equilibrated for $16 \mathrm{~h}$ at a specific $\mathrm{pH}$ (in PBS buffer only) and the dimer fraction from the SEC taken for grid preparation. Cu/Rh 1.2/1.3 300 mesh grids were plasma cleaned for 90 s at 30\% plasma power (80:20 argon:oxygen). The protein concentration was adjusted to $1 \mu \mathrm{M}$ and applied on the grid and plunge-frozen in a Vitrobot Mark IV robot (FEI), maintained at $100 \%$ humidity and $10{ }^{\circ} \mathrm{C}$.

\section{CryoEM data collection and image analysis}

Datasets for BicD2 at $\mathrm{pH} 8.0$ and $\mathrm{pH} 7.0$ were collected using a Glacios ${ }^{\mathrm{TM}}$ Cryo-TEM operating at $200 \mathrm{keV}$ with a K2 Summit direct electron detector (Gatan). Videos were collected in counting mode, with a final calibrated pixel size of $1.078 \AA /$ pixel, 8 s exposure, and total dose of $\sim 54 \mathrm{e}^{-/ \AA^{2}}$.

SerialEM was used for automated data collection and the videos were processed using Relion3.0. ${ }^{50}$ The micrographs were manually filtered giving each dataset $\sim 700$ micrographs. Particles were picked using the general model in TOPAZ and 2D classified twice. Each dataset yielded around 150k particles used for 2D classification. All data processing steps were done reference-free.

\section{In vitro kinase assays and phosphorylation mapping}

BicD2 or RanBP2 ${ }_{\mathrm{BBD}}$ were mixed with CDK1 at 1:100 molar ratio with 0.1mM MgATP and incubated for $30 \mathrm{~min}$ at RT. Each sample had a negative control that did not contain MgATP. Each reaction mixture was loaded on SDS-PAGE and stained with pro-Q diamond stain to check for phosphorylated proteins. Phosphorylatoin sites were analysed with trypsin digest MS using an Orbitrap Elite and Acclaim Pepmap 100 column. The PSM 
values corresponded to the number of MS2 spectra which made it possible to identify peptides. In BicD2 we covered 75\% of the sequence (PSM's: 2087) while for RanBP2 we covered 85\% (PSM's: 1195).

\section{AlphFold2 structure prediction}

We used the whole CC2 and CC3 domain of a human BicD2 (residues 265-855) to model a homooligomer. We generated 5 models using AlphaFold2_advanced notebook from Google Colab. We used MMseqs2 (UniRef+Environmental) for MSA generation. 


\section{REFERENCES}

1. Reck-Peterson, S. L., Redwine, W. B., Vale, R. D. \& Carter, A. P. The cytoplasmic dynein transport machinery and its many cargoes. Nat. Rev. Mol. Cell Biol. (2018). doi:10.1038/s41580-018-0004-3

2. Paschal, B. M. \& Vallee, R. B. Retrograde transport by the microtubule-associated protein MAP 1C. Nature 330, 181-183 (1987).

3. Dodding, M. P. \& Way, M. Coupling viruses to dynein and kinesin-1. EMBO Journal 30, 3527-3539 (2011).

4. Wilson, M. H. \& Holzbaur, E. L. F. Opposing microtubule motors drive robust nuclear dynamics in developing muscle cells. J. Cell Sci. 125, 4158-4169 (2012).

5. Fu, M. meng \& Holzbaur, E. L. F. Integrated regulation of motor-driven organelle transport by scaffolding proteins. Trends in Cell Biology 24, 564-574 (2014).

6. Schiavo, G., Greensmith, L., Hafezparast, M. \& Fisher, E. M. C. Cytoplasmic dynein heavy chain: The servant of many masters. Trends in Neurosciences 36, 641-651 (2013).

7. D, S. et al. Bicaudal D2, dynein, and kinesin-1 associate with nuclear pore complexes and regulate centrosome and nuclear positioning during mitotic entry. PLoS Biol. $\mathbf{8}$, (2010).

8. Hu, D. J. K. et al. XDynein recruitment to nuclear pores activates apical nuclear migration and mitotic entry in brain progenitor cells. Cell 154, 1300 (2013).

9. Baffet, A. D., Hu, D. J. \& Vallee, R. B. Cdk1 Activates Pre-mitotic Nuclear Envelope Dynein Recruitment and Apical Nuclear Migration in Neural Stem Cells. Dev. Cell 33, 703-716 (2015).

10. Shu, T. et al. Ndel1 operates in a common pathway with LIS1 and cytoplasmic dynein to regulate cortical neuronal positioning. Neuron 44, 263-277 (2004).

11. Tsai, J. W., Chen, Y., Kriegstein, A. R. \& Vallee, R. B. LIS1 RNA interference blocks neural stem cell division, morphogenesis, and motility at multiple stages. J. Cell Biol. 170, 935-945 (2005).

12. Toyo-Oka, K. et al. Recruitment of katanin $\mathrm{p} 60$ by phosphorylated NDEL1, an LIS1 interacting protein, is essential for mitotic cell division and neuronal migration. Hum. Mol. Genet. 14, 3113-3128 (2005).

13. JB, G. et al. Molecular mechanism of dynein recruitment to kinetochores by the RodZw10-Zwilch complex and Spindly. J. Cell Biol. 216, 943-960 (2017).

14. IG, L. et al. A conserved interaction of the dynein light intermediate chain with dyneindynactin effectors necessary for processivity. Nat. Commun. 9, (2018).

15. Celestino, R. et al. A transient helix in the disordered region of dynein light intermediate chain links the motor to structurally diverse adaptors for cargo transport. PLoS Biol. 17, (2019).

16. Zhang, K. et al. Cryo-EM Reveals How Human Cytoplasmic Dynein Is Auto-inhibited and Activated. Cell 169, 1303-1314.e18 (2017). 
17. Torisawa, T. et al. Autoinhibition and cooperative activation mechanisms of cytoplasmic dynein. Nat. Cell Biol. 20141611 16, 1118-1124 (2014).

18. PM, H. et al. Purification, cloning, and characterization of Nek8, a novel NIMA-related kinase, and its candidate substrate Bicd2. J. Biol. Chem. 277, 16229-16240 (2002).

19. $\mathrm{G}, \mathrm{N}$. et al. Exome sequencing links corticospinal motor neuron disease to common neurodegenerative disorders. Science 343, 506-511 (2014).

20. K, P. et al. Novel mutations in the DYNC1H1 tail domain refine the genetic and clinical spectrum of dyneinopathies. Hum. Mutat. 36, 287-291 (2015).

21. K, P. et al. Molecular defects in the motor adaptor BICD2 cause proximal spinal muscular atrophy with autosomal-dominant inheritance. Am. J. Hum. Genet. 92, 955-964 (2013).

22. Designed Research; A, E. M. C. D. Bicaudal D2 facilitates the cytoplasmic trafficking and nuclear import of HIV-1 genomes during infection. doi:10.1073/pnas.1712033114

23. Wu, Y. K., Umeshima, H., Kurisu, J. \& Kengaku, M. Nesprins and opposing microtubule motors generate a point force that drives directional nuclear motion in migrating neurons. Dev. 145, (2018).

24. Gonçalves, J. C., Quintremil, S., Yi, J. \& Vallee, R. B. Nesprin-2 Recruitment of BicD2 to the Nuclear Envelope Controls Dynein/Kinesin-Mediated Neuronal Migration In Vivo. Curr. Biol. 30, 3116-3129.e4 (2020).

25. W, H. \& RD, V. Disease-associated mutations in human BICD2 hyperactivate motility of dynein-dynactin. J. Cell Biol. 216, 3051-3060 (2017).

26. Terawaki, S. I., Yoshikane, A., Higuchi, Y. \& Wakamatsu, K. Structural basis for cargo binding and autoinhibition of Bicaudal-D1 by a parallel coiled-coil with homotypic registry. Biochem. Biophys. Res. Commun. 460, 451-456 (2015).

27. Liu, Y. et al. Bicaudal-D uses a parallel, homodimericcoiled coil with heterotypic registry tocoordinate recruitment of cargos to dynein. Genes Dev. 27, 1233-1246 (2013).

28. Dienstbier, M. \& Li, X. Bicaudal-D and its role in cargo sorting by microtubule-based motors. in Biochemical Society Transactions 37, 1066-1071 (Portland Press, 2009).

29. Hoogenraad, C. C. et al. Mammalian golgi-associated Bicaudal-D2 functions in the dynein-dynactin pathway by interacting with these complexes. EMBO J. 20, 4041-4054 (2001).

30. Hoogenraad, C. C. et al. Bicaudal D induces selective dynein-mediated microtubule minus end-directed transport. EMBO J. 22, 6004-6015 (2003).

31. Matanis, T. et al. Bicaudal-D regulates COPI-independent Golgi-ER transport by recruiting the dynein-dynactin motor complex. Nat. Cell Biol. 4, 986-992 (2002).

32. Moorhead, A. R., Rzomp, K. A. \& Scidmore, M. A. The Rab6 effector bicaudal D1 associates with Chlamydia trachomatis inclusions in a biovar-specific manner. Infect. Immun. 75, 781-791 (2007).

33. Stuurman, N. et al. Interactions between coiled-coil proteins: Drosophila lamin Dm0 binds to the Bicaudal-D protein. Eur. J. Cell Biol. 78, 278-287 (1999).

34. Noell, C. R. et al. Role of Coiled-Coil Registry Shifts in the Activation of Human Bicaudal 
D2 for Dynein Recruitment upon Cargo Binding. J. Phys. Chem. Lett. 10, 4362-4367 (2019).

35. Jumper, J. et al. Highly accurate protein structure prediction with AlphaFold. Nat. 2021 17 (2021). doi:10.1038/s41586-021-03819-2

36. Gibson 1\$, J. M. et al. Coil-to-Helix Transition at the Nup358-BicD2 Interface for Dynein Recruitment and Activation. bioRxiv 2021.05.06.443034 (2021). doi:10.1101/2021.05.06.443034

37. Veld, P. J. H. in 't et al. Reconstitution and use of highly active human CDK1:CyclinB:CKS1 complexes. bioRxiv 2021.09.24.461690 (2021). doi:10.1101/2021.09.24.461690

38. Olenick, M. A. \& Holzbaur, E. L. F. Dynein activators and adaptors at a glance. J. Cell Sci. 132, (2019).

39. Sladewski, T. E. et al. Recruitment of two dyneins to an mRNA-dependent bicaudal D transport complex. Elife 7, (2018).

40. Gagliardi, L. J. \& Shain, D. H. Is intracellular pH a clock for mitosis? Theor. Biol. Med. Model. 10, 8 (2013).

41. Pouysségur, J., Franchi, A., L'Allemain, G. \& Paris, S. Cytoplasmic $\mathrm{pH}$, a key determinant of growth factor-induced DNA synthesis in quiescent fibroblasts. FEBS Lett. 190, 115119 (1985).

42. Chambard, J. C. \& Pouyssegur, J. Intracellular $\mathrm{pH}$ controls growth factor-induced ribosomal protein $\mathrm{S} 6$ phosphorylation and protein synthesis in the $\mathrm{G} 0 \rightarrow \mathrm{G} 1$ transition of fibroblasts. Exp. Cell Res. 164, 282-294 (1986).

43. Y, L. et al. Bicaudal-D uses a parallel, homodimeric coiled coil with heterotypic registry to coordinate recruitment of cargos to dynein. Genes Dev. 27, 1233-1246 (2013).

44. MA, M. et al. RNA-directed activation of cytoplasmic dynein-1 in reconstituted transport RNPs. Elife 7, (2018).

45. PM, H. et al. Purification, cloning, and characterization of Nek8, a novel NIMA-related kinase, and its candidate substrate Bicd2. J. Biol. Chem. 277, 16229-16240 (2002).

46. Van Damme, P. et al. N-terminal acetylome analyses and functional insights of the Nterminal acetyltransferase NatB. Proc. Natl. Acad. Sci. U. S. A. 109, 12449-12454 (2012).

47. Seale, J. W. The role of a conserved histidine-tyrosine interhelical interaction in the ion channel domain of $\delta$-endotoxins from Bacillus thuringiensis. Proteins Struct. Funct. Bioinforma. 63, 385-390 (2006).

48. Rogerson, D. T. et al. Efficient genetic encoding of phosphoserine and its nonhydrolyzable analog. Nat. Chem. Biol. 2015 117 11, 496-503 (2015). 

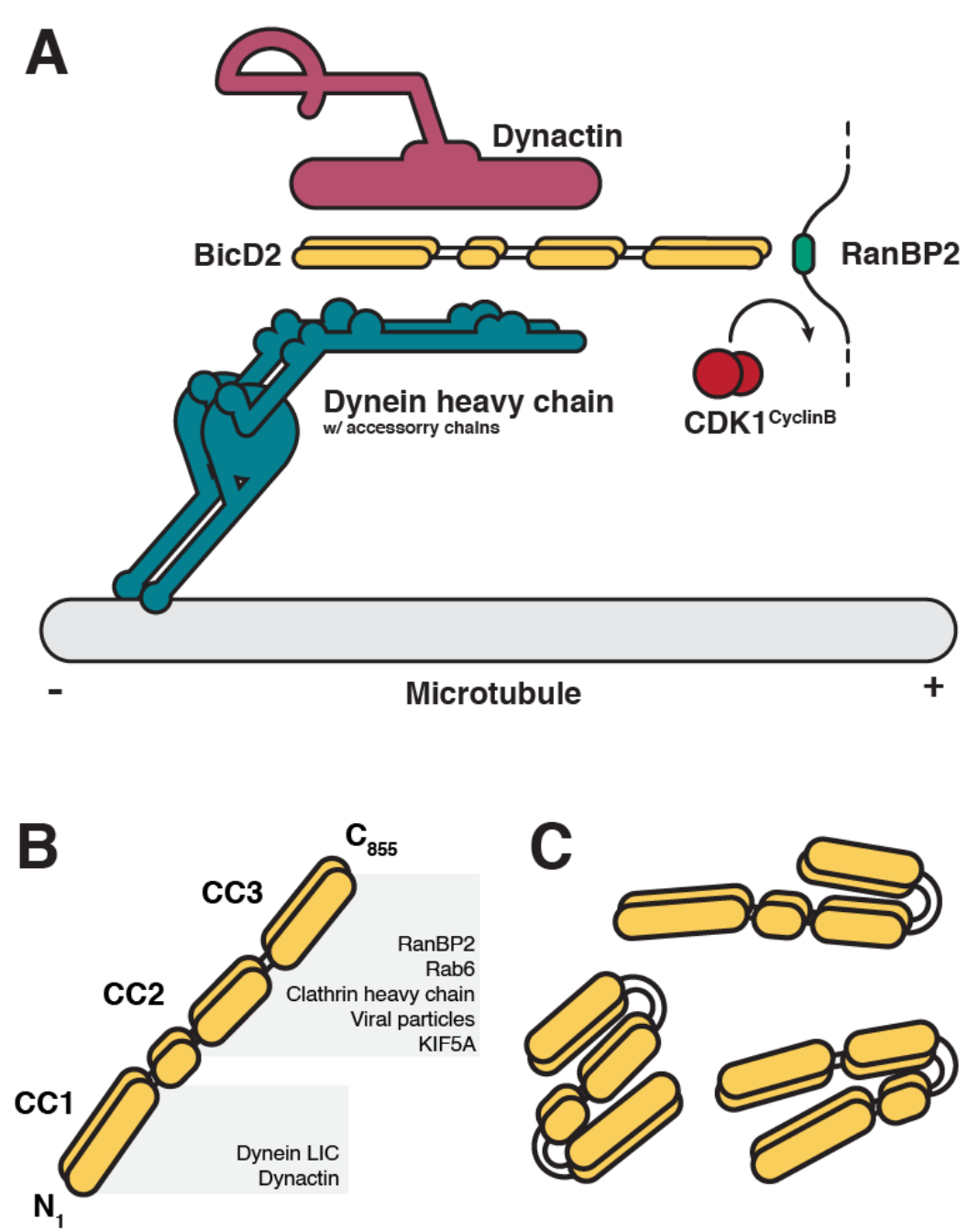

Figure 1. A Schematic representation of the dynein-dynactin-BicD2 complex associated with the cargo protein - RanBP2. CDK1 ${ }^{\text {CyclinB }}$ activity has been known to activate this complex to progressively move the nucleus in radial glial progenitor cells towards the base of the neocortex in the developing human brain. B Domain organization of the BicD2 cargo adaptor dimer. The N-terminal part is responsible for binding dynein and dynactin while the C-terminal part binds plus-end directed motor kinesin-1 and cargos. C Hypothetical BicD2 autoinhibited conformations from the previously reported data. 

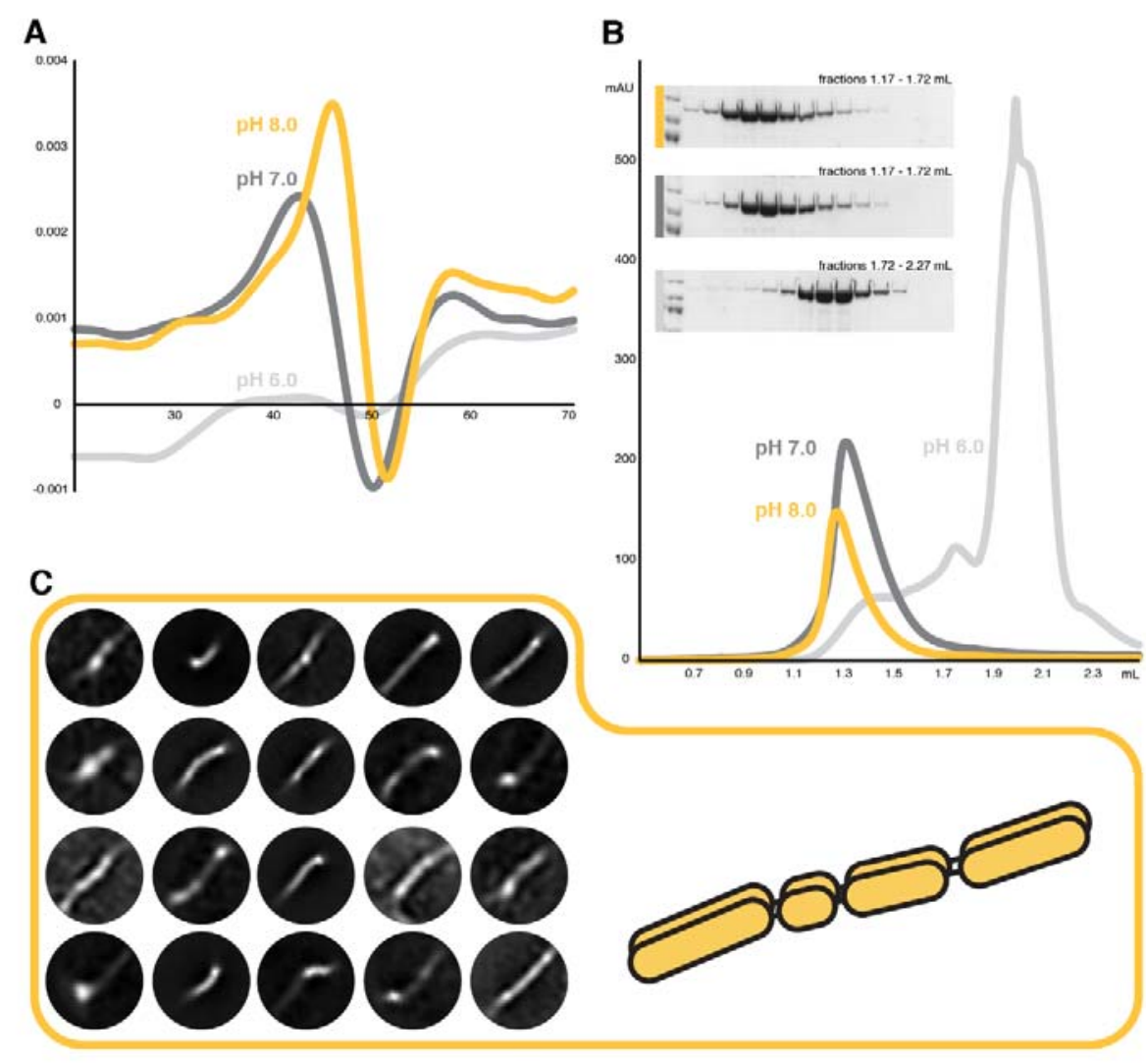

D

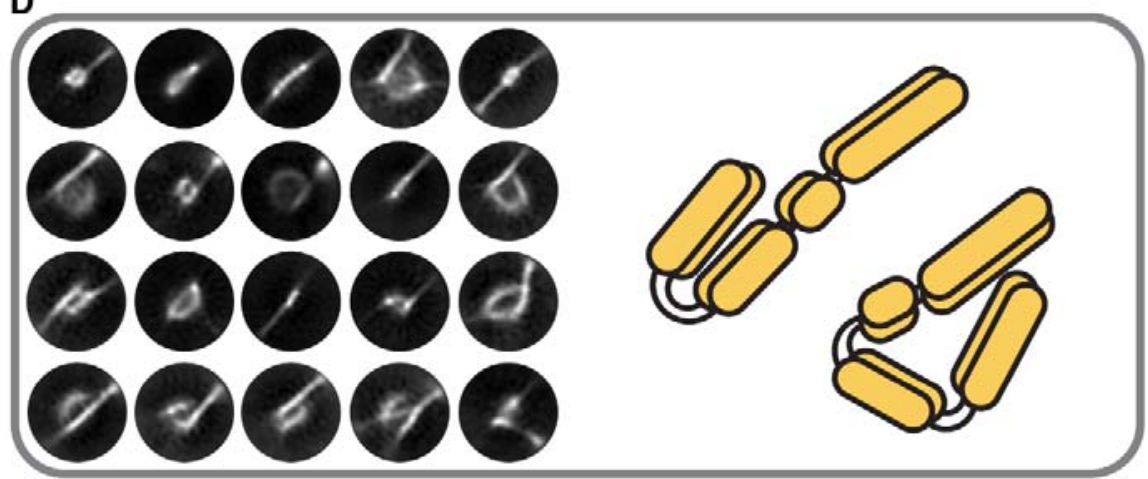

Figure 2. A First-derivative of the DSF melting curves at three different $\mathrm{pH}$ values. The curves at $\mathrm{pH} 7.0$ and $\mathrm{pH} 8.0$ display main inflection point in the range of $47-50^{\circ} \mathrm{C}$. The curve at $\mathrm{pH} 6.0$ doesn't show a distinct inflection point. Each measurement was repeated 3 times. $B$ SEC profiles of BicD2 run at three different $\mathrm{pH}$ values. Each sample was run twice on a Superose ${ }^{\circledR} 6$ Increase column to ensure clean peak fractions. C and D Representative cryoEM 2D classes from $\sim 700$ micrographs (per $\mathrm{pH}$ condition). The yellow box represents classes from $\mathrm{pH} 8.0$ while the grey box from $\mathrm{pH}$ 7.0. In both cases we processed the data with Relion3.1. 
bioRxiv preprint doi: https://doi.org/10.1101/2022.01.05.474964; this version posted January 5, 2022. The copyright holder for this preprint

(which was not certified by peer review) is the author/funder, who has granted bioRxiv a license to display the preprint in perpetuity. It is made available under aCC-BY-NC 4.0 International license.

A

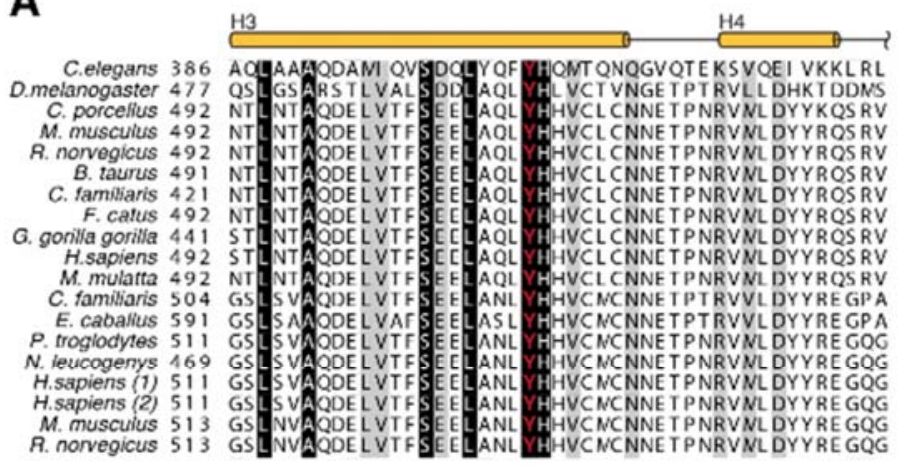

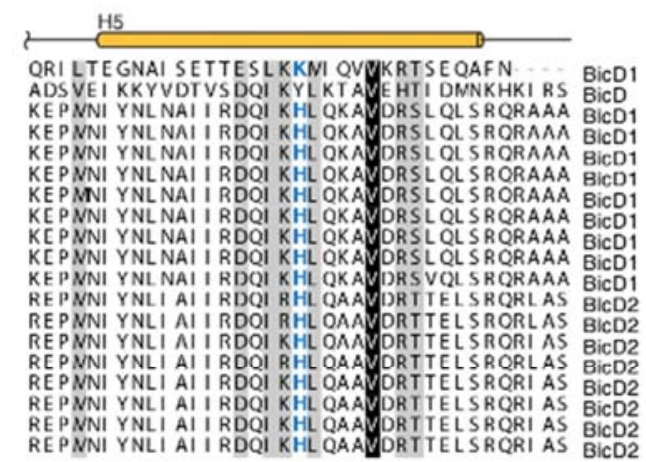

B

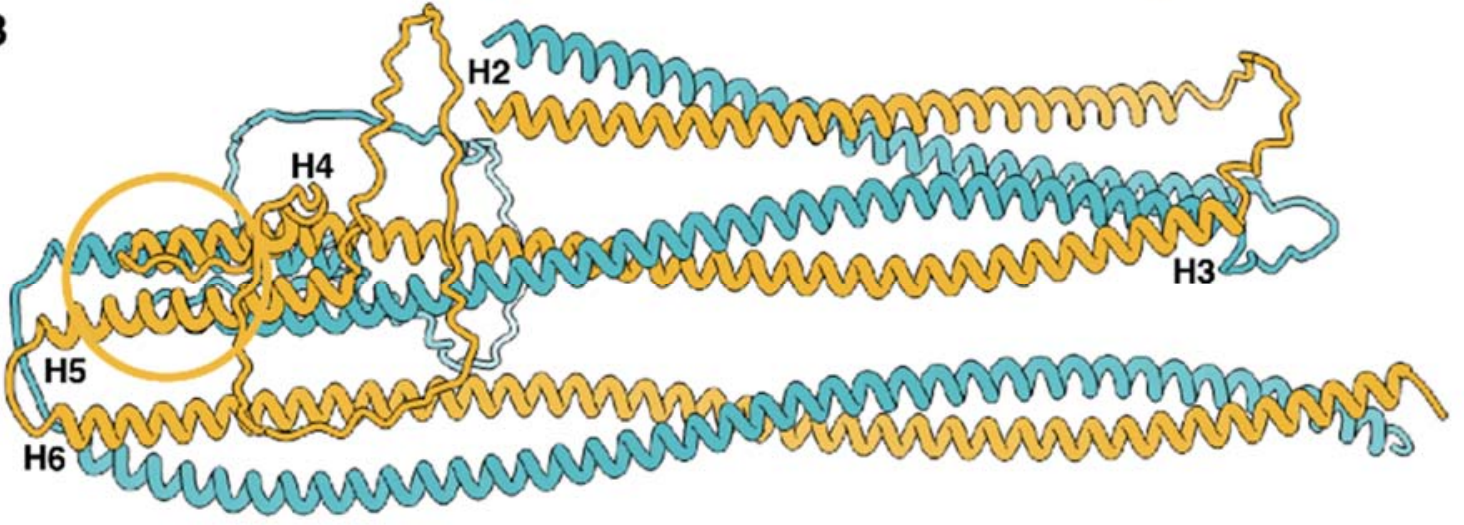

CC1

CC2

CC3

$\mathrm{N}_{1}$

H1

- H2

H3

H4 - $\mathrm{H} 5$

H6

$\mathrm{C}_{855}$

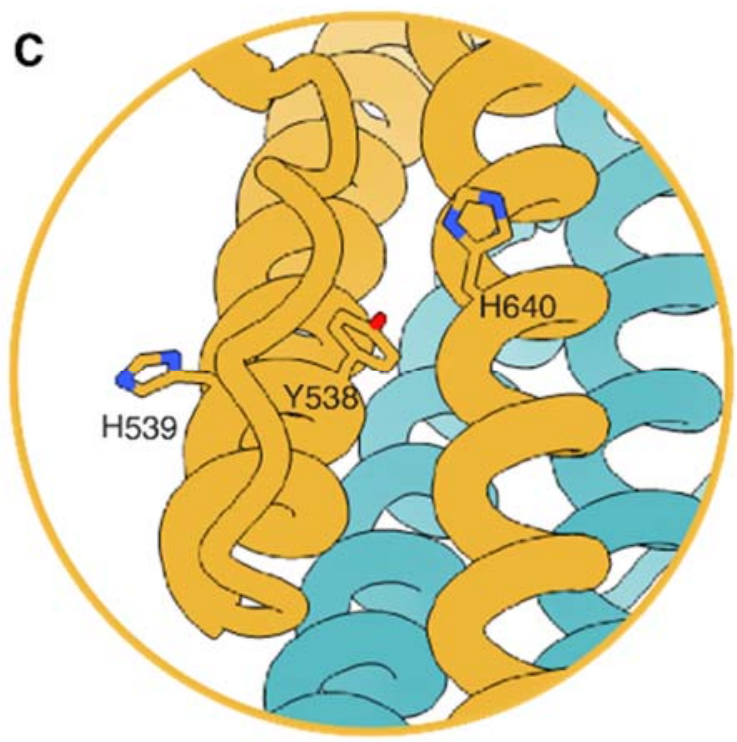

D

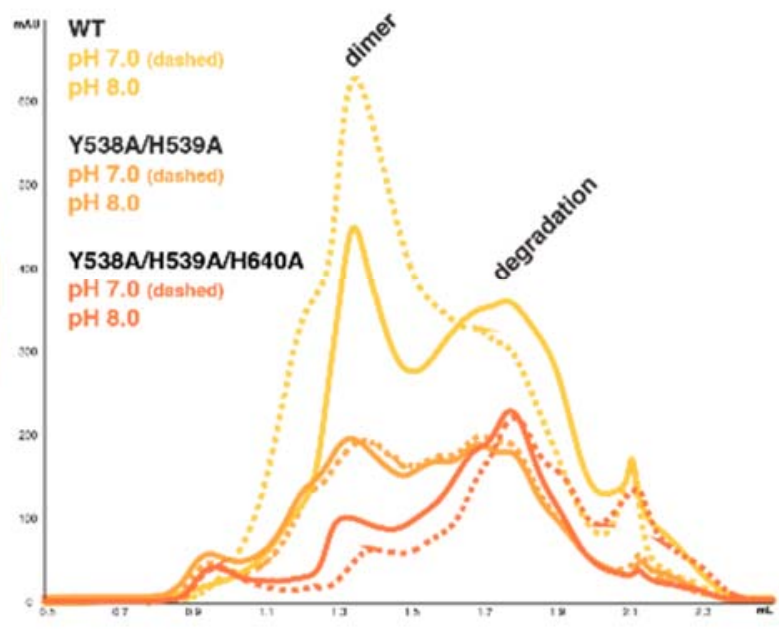


Figure 3. A Sequence alignment of the tri-helical domain $(\mathrm{H} 3, \mathrm{H} 4$, and $\mathrm{H} 5$ helix $)$ of $D$. melanogaster, C. elegans, and mammalian BicD1 and BicD2 isoforms. The conserved Y538 is marked in red, and $\mathrm{H} 640$ in blue. B Structure prediction of the BicD2 CC2 and CC3 dimer with AlphaFold2. The C-terminal loop of CC3 has been deleted for clarity reasons. $\mathbf{C}$ Zoom into the conserved histidine and tyrosine that are crucial for the protein stability. D Chromatograms of affinity purified BicD2 variants. In yellow - WT, orange - Y538A/H539A double mutant, dark orange - Y538A/H539A/H640A triple mutant. In all chromatograms the solid line represents $\mathrm{pH} 8.0$, and the dashed line $\mathrm{pH}$ 7.0. For each construct an identical protein amount was loaded. 
A
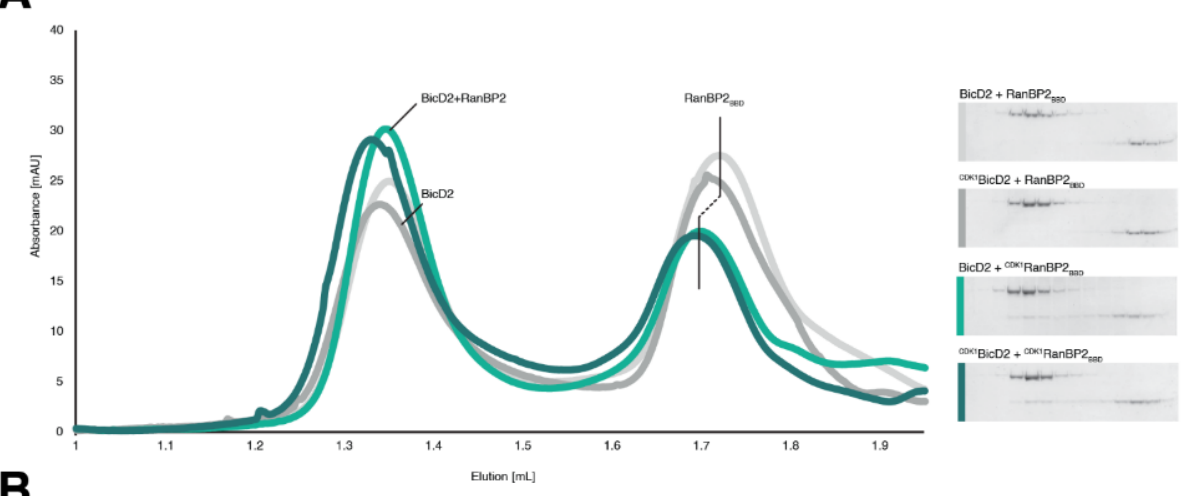

B
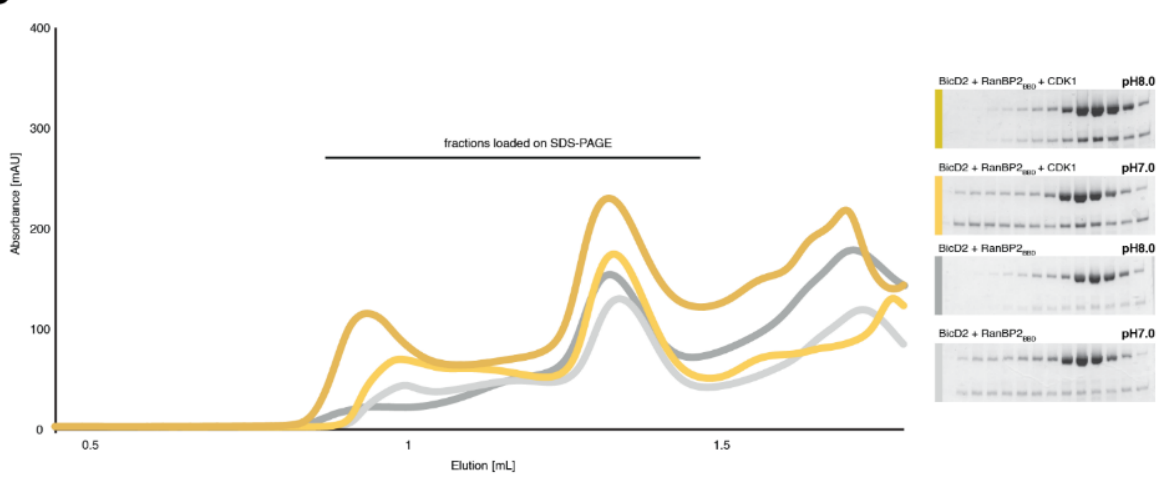

Figure 4. SEC profiles of the BicD2 reaction with RanBP2BBD with or without action of the CDK1 1 cyclinB complex. A Purified proteins were mixed at a $1: 1$ molar ratio and incubated for 30 minutes at RT. In light grey a chromatogram of unphosphorylated BicD2 and unphosphorylated RanBP2 $2_{\text {BBD. In }}$ dark grey CDK1 ${ }^{\text {CyclinB }}$ phosphorylated BicD2 with unphosphorylated RanBP2. In light green unphosphorylated BicD2 with CDK1 1 yclinB phosphorylated RanBP2, and dark green represents both proteins being CDK1 $1^{\text {CyclinB }}$ phosphorylated. All reactions were performed at $\mathrm{pH}$ 8.0 B Pull-down of affinity-purified BicD2, RanBP2 $\mathrm{BBD}$, at two different $\mathrm{pH}$ values with or without CDK1 $1_{\text {CyclinB }}$. The dark yellow chromatogram represents BicD2, RanBP2 ${ }_{\mathrm{BBD}}$, and CDK1 1 cyclinB pull-down at $\mathrm{pH} 8.0$, while light yellow shows the same reaction but at $\mathrm{pH}$ 7.0. Dark and light grey chromatogram show the same reactions but without activity of $\mathrm{CDK} 1{ }^{\text {CyclinB }}$ complex (at pH 8.0 and $\mathrm{pH} 7.0$ respectively). 


\section{Supplementary figures}
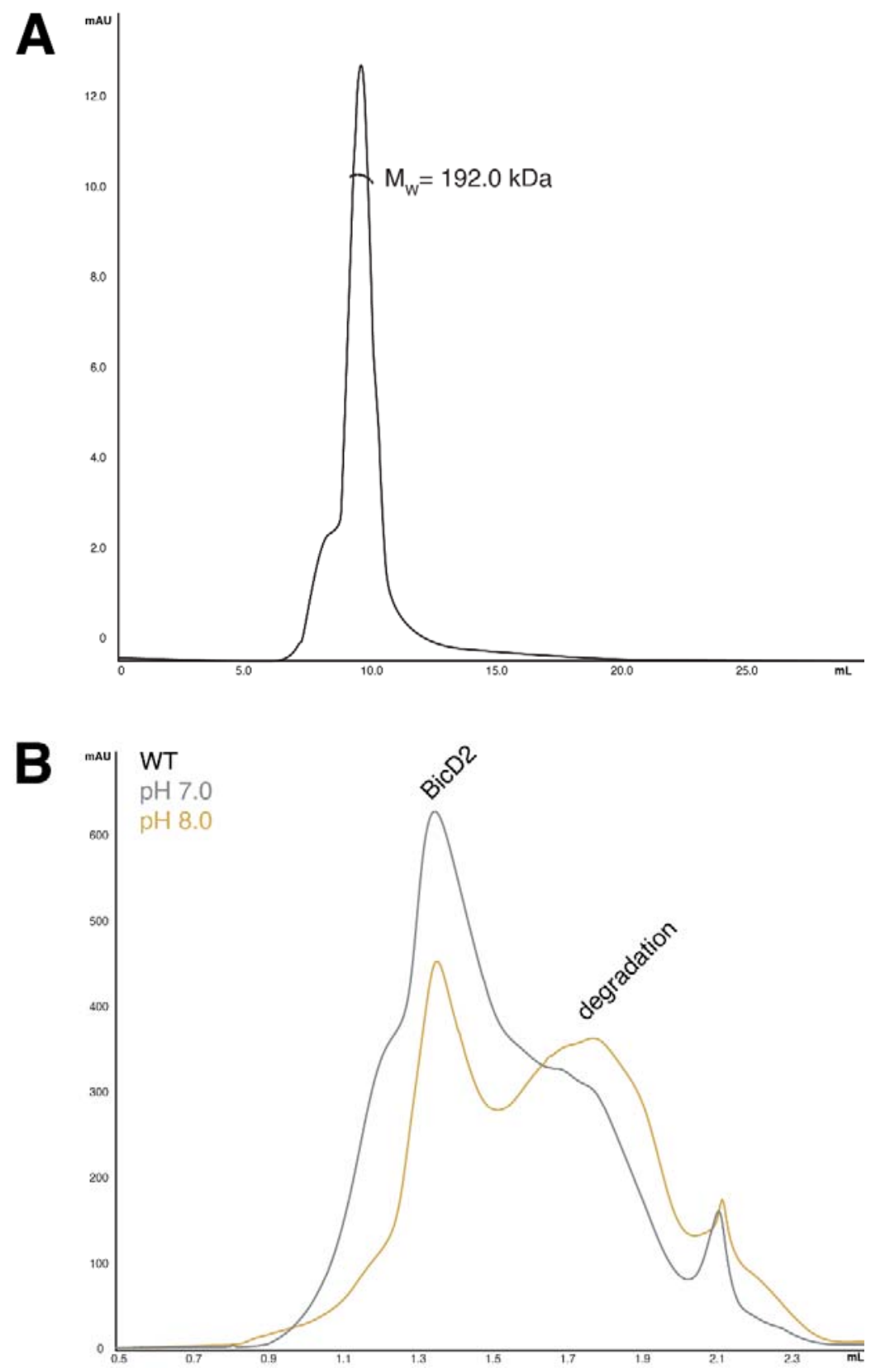

Supplementary figure 1. A The SEC-MALS profile of the pre-purified BicD2. B The SEC profile of an affinity purified full-length BicD2. The grey

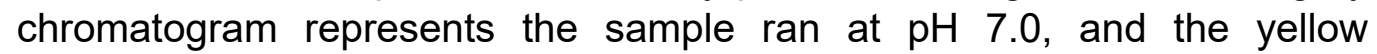
chromatogram is the sample ran at $\mathrm{pH}$ 8.0. In both cases an identical protein amount was loaded on to the Superose ${ }^{\circledR} 6$ Increase column. 

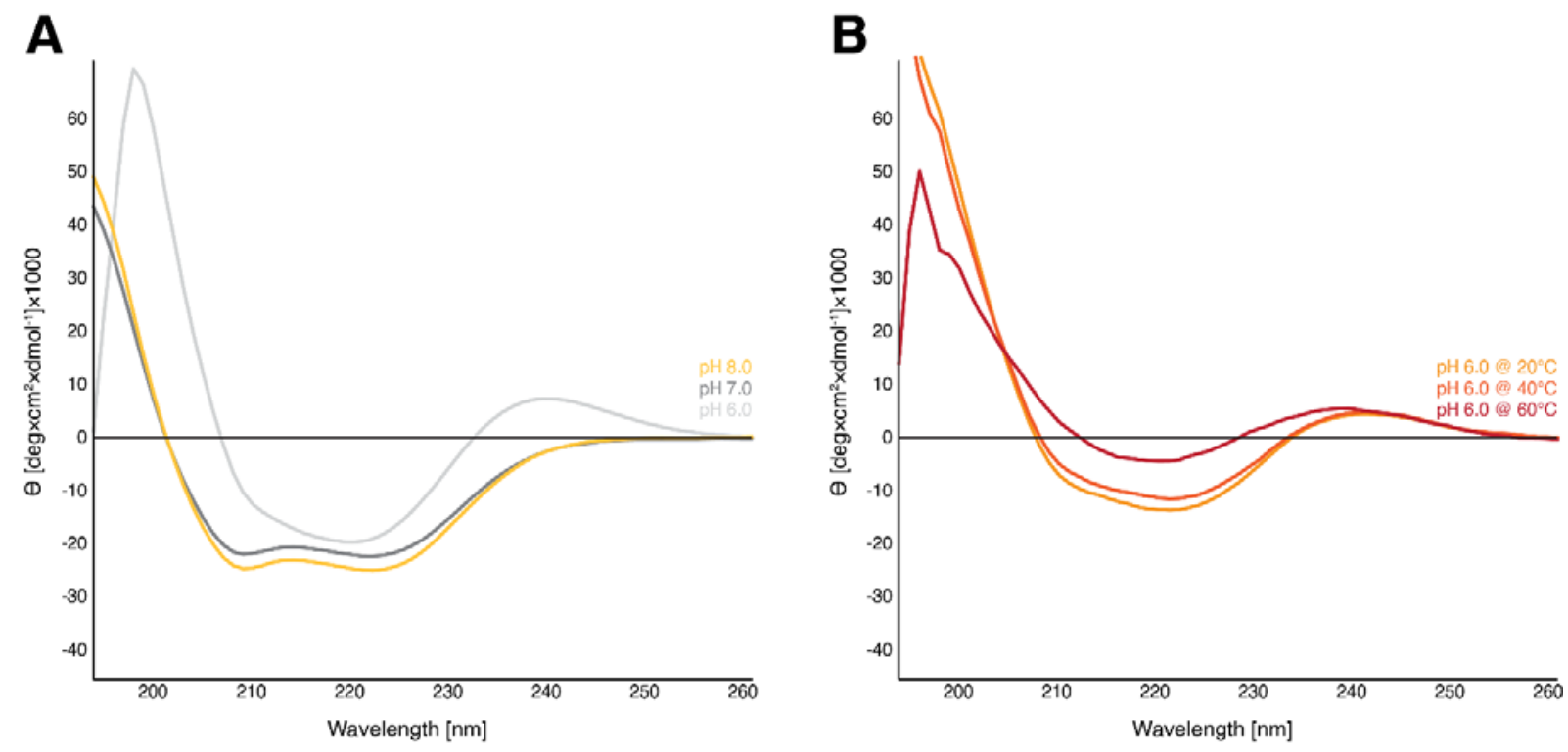

Supplementary figure 2. A CD spectra of the full-length BicD2 at $\mathrm{pH}$ value of 6.0 , $\mathrm{pH} 7.0$, and $\mathrm{pH} 8.0$. All three runs were done at $20^{\circ} \mathrm{C}$. B CD spectra of the full-length BicD2 at $\mathrm{pH} 6.0$ at three temperatures $\left(20,40\right.$, and $\left.60^{\circ} \mathrm{C}\right)$. Prior to the experiment each BicD2 sample was run twice on SEC in PBS buffer at the respective $\mathrm{pH}$. 


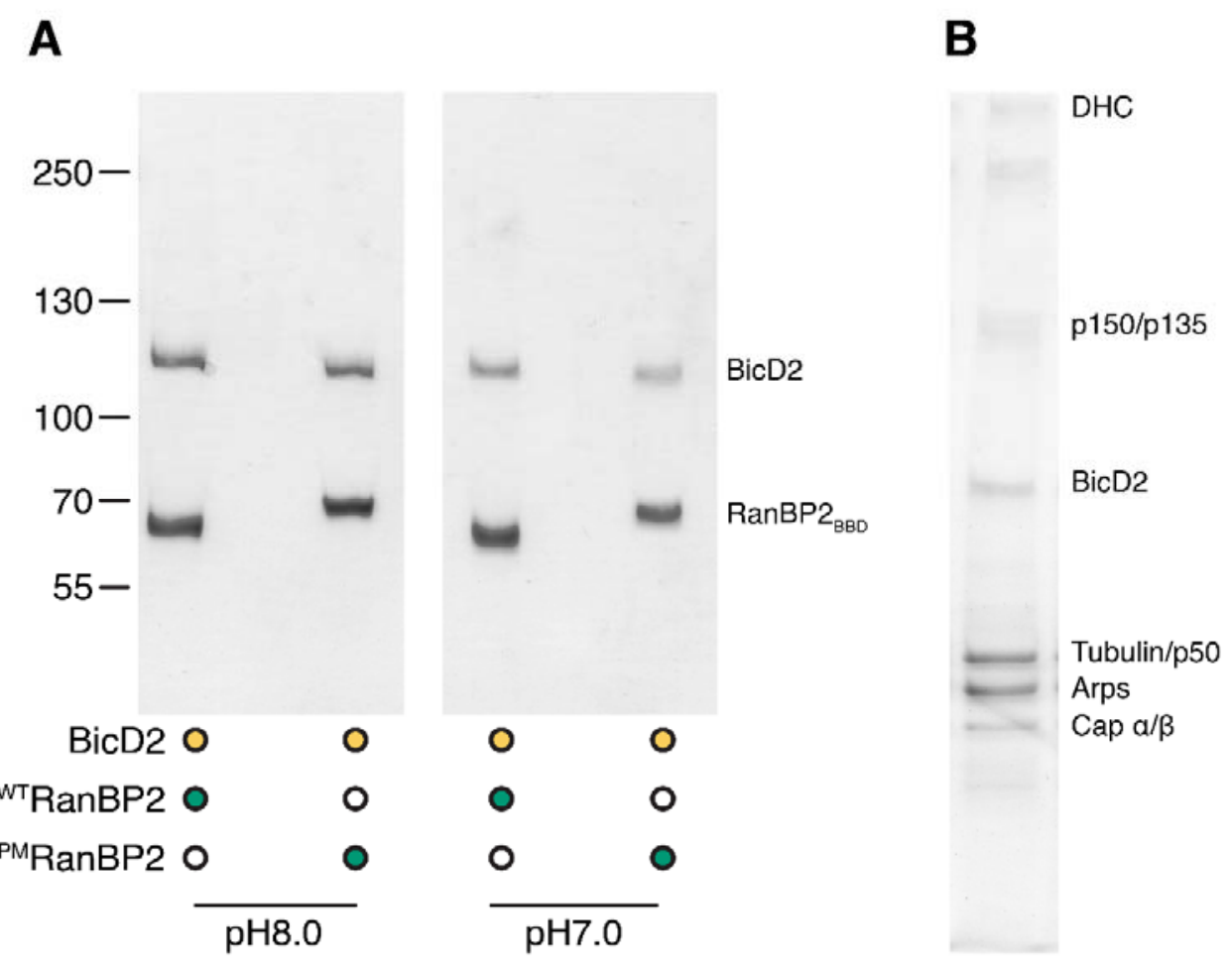

Supplementary figure 3. A The double pull-down of the BicD2-RanBP2BBD complex. The first pull-down was done on Strep-tagged BicD2 followed by 6xHis-tagged RanBP2. The complex was pulled with either RanBP2 $2_{\mathrm{BBD}}\left(\mathrm{R}_{\mathrm{anBP}} 2_{\mathrm{BBD}}-\mathrm{WT}\right)$ or the phosphomimetic mutant of RanBP2 ${ }_{B B D}$ (RanBP2 $\left.{ }_{B B D}-P M\right)$ and at two different $\mathrm{pH}$ values. $\mathbf{B}$ The BicD2 pull-down from the rat brain lysate indicating the DDB complex characteristic bands. The dynein heavy chain and p150 bands were confirmed by MS. 

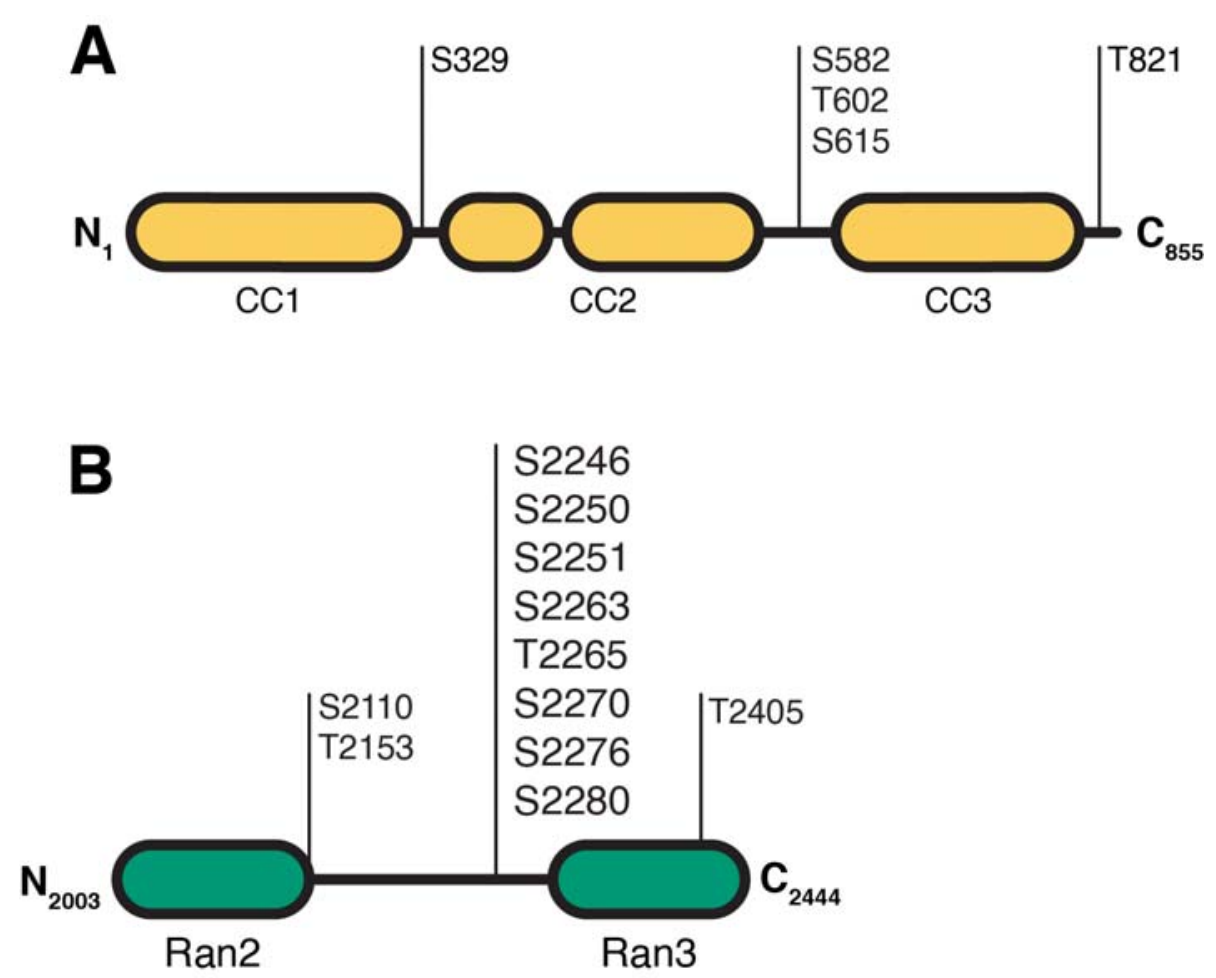

Supplementary figure 4. CDK1-CyclinB phosphorylation profile of BicD2 and RanBP2. A BicD2 contains five S/T sites within its sequence in structurally disordered regions. B RanBP2 $2_{\mathrm{BBD}}$ contains multiple phosphorylation sites within the structurally disordered region between the Ran2 and Ran3 domains, which is also the BicD2 binding site. 


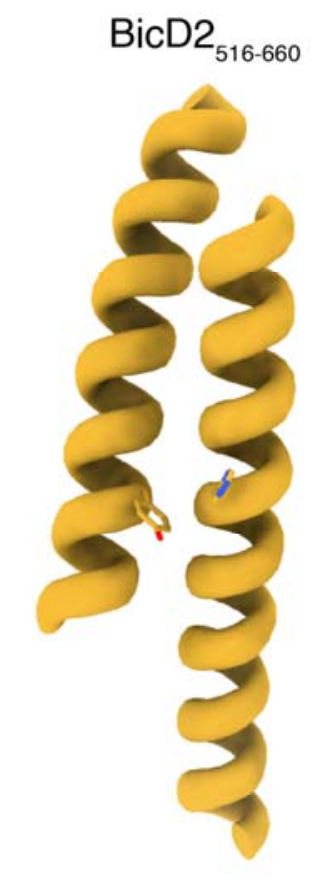

${\text { Cry3 } 3 b_{122-220}}$
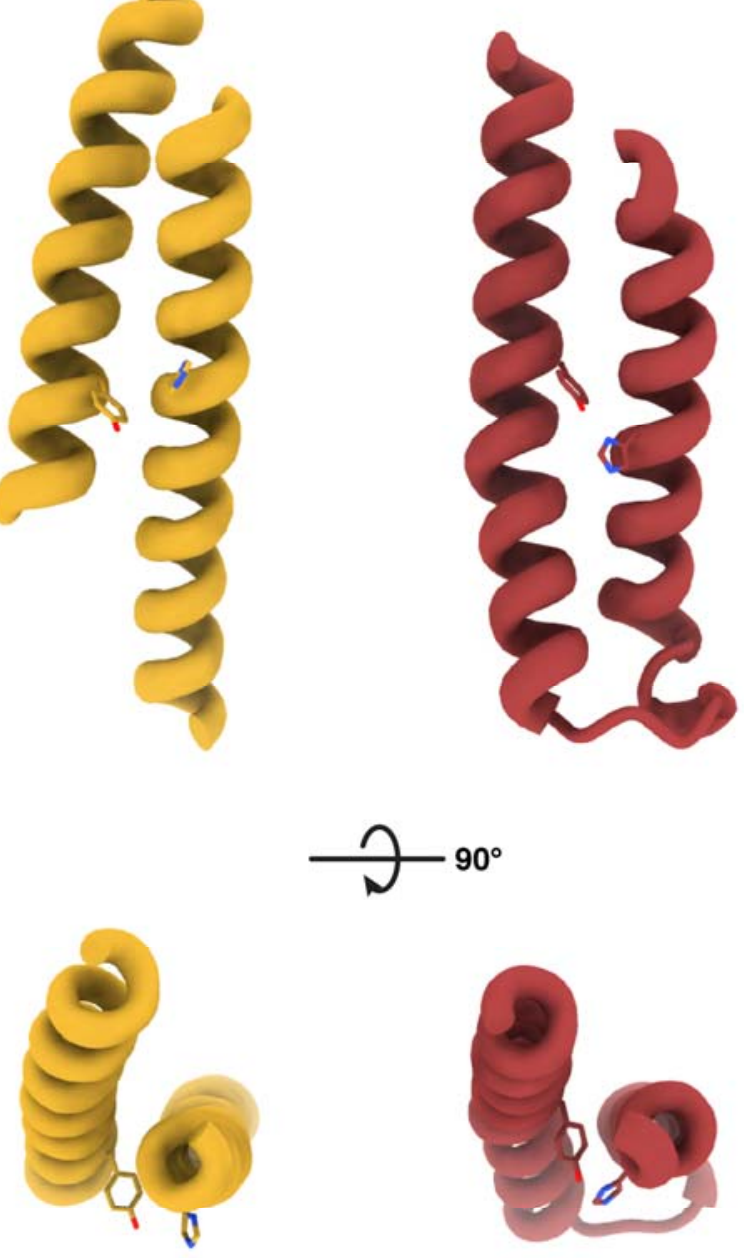

212 QVFGEEWGYSSEDVAEFYHRQLKLTQQYTDH-CVNWYNVGLNGLRGST 259

521 SVAQDELVTESEETAANT HHVCMCNNETPNRVMTDYYREGQGGAGRTS 568

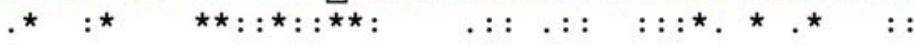

Supplementary figure 5. Structure comparison of the computational structure of BicD2 H3-H4-H5 a-helical bundle fragment and analogous region in Cry3Bb endotoxin (PDB ID: 1CIY). Loops removed for clarity reasons. (Bottom) Sequence alignment of the tyrosine containing helix. 